sealants were significantly more effective. ${ }^{4}$ Replacements of sealant because of partial or total losses, as well as re-applications of varnish, were undertaken at the six-monthly recall periods during the study in order to maintain effective protection. A recent commentary ${ }^{5}$ concluded that a systematic review ${ }^{6}$ was unable to show conclusive evidence of the benefit of fluoride varnish for preschool children. There appear to be no cost-effective analyses from general dental practices of various fluoride treatments for occlusal fissures in adults, and scant information for such treatments in preschool and older children and adolescents. ${ }^{7}$ Earlier studies of pit and fissure sealant use were also unable to demonstrate their cost-effectiveness, which only became possible following sealant placement in targeted high-risk to caries child and adolescent populations, individuals, teeth and fissures soon after complete tooth eruption..$^{8}$ Recommendations for the placement of sealants in adults are based on very low-quality evidence and are largely extrapolated from studies in children and adolescents. ${ }^{8,9}$ Because of the problems identified in our article in adequately sealing fissures and maintaining sealants in adults, we have stated our general preference in adults for minimally invasive narrow fissure fillings employing a suitable flowable resin-based composite.

Initially, pit and fissure sealants were only advocated as a preventive treatment, but dentists have been inadvertently sealing in active caries as a therapeutic measure since sealants were first introduced. This usage has now gained research acceptance for the deliberate sealing in of small noncavitated carious lesions (supposedly) confined to enamel. ${ }^{9}$ Higher $k V p$ X-ray machines, faster analogue film speeds and digital radiography with reduced image contrast have increased the difficulty in detecting occlusal lesions extending into dentine, and which may be far more extensive than visualised either radiographically or clinically. Concerns by dental practitioners regarding sealants continue to be expressed ${ }^{10}$ and, in a recent survey, very few general and paediatric dentists would place an occlusal sealant in a non-cavitated premolar or molar when, radiographically, caries extended into dentine. ${ }^{11}$

Dental practitioners have also been either inadvertently or deliberately leaving residual caries in prepared teeth ever since restorations were first placed. Readers are referred to indirect pulp capping (preventive endodontics) and the stepwise removal of infected carious tissue included in Chapter 12 of the textbook, and which is not part of the current series of articles. The procedure relies on the maintenance of the cavity seal, and has been used and taught by us since the early 1970s following the pioneering research of Maury Massler (1967). ${ }^{12}$ We concur with the sentiments expressed in the final sentence of the letter.

1. Yip K, Smales R. Oral diagnosis and treatment planning: part 2. Dental caries and assessment of risk. Br Dent J 2012;213: 59-66.

2. Marinho VCC. Cochrane reviews of randomized trials of fluoride therapies for preventing dental caries. Eur Arch Paediatr Dent 2009; 10: 183-191.

3. Hiiri A, Ahovuo-Saloranta A, Nordblad A, Mäkelä $M$. Pit and fissure sealants versus fluoride varnishes for preventing dental decay in children and adolescents. Cochrane Database Syst Rev 2006; CD0-003067.

4. Bravo M, Garcia-Anllo I, Baca P, Llodra J C. A 48-month survival analysis comparing sealant (Delton) with fluoride varnish (Duraphat) in 6- to 8 -year-old children. Community Dent Oral Epidemiol 1997; 25: 247-250

5. O'Keefe E. Fluoride varnish may be effective in preschoolers. Questions: Does fluoride varnish decrease the incidence of caries in preschool children? Evid Based Dent 2011; 12: 41-42.

6. Carvalho D M, Salazar M, Oliveira B H, Coutinho ES. Fluoride varnishes and decrease in caries incidence in preschool children: a systematic review. Rev Bras Epidemiol 2010; 13: 139-149.

7. Arrow P. Cost minimisation analysis of two occlusal caries preventive programmes. Community Dent Health 2000; 17: 85-91.

8. Azarpazhooh A, Main PA. Pit and fissure sealants in the prevention of dental caries in children and adolescents: a systematic review. J Can Dent Assoc 2008;74: 171-177.

9. Beauchamp J, Caufield PW, Crall J J et al. Evidencebased clinical recommendations for the use of pit-and-fissure sealants. A report of the American Dental Association Council on Scientific Affairs. J Am Dent Assoc 2008; 139: 257-268.

10. Lodico D J. Pit and fissure sealants. Letter. J Am Dent Assoc 2008; 139: 660-662.

11. Tellez M, Gray SL, Gray S, Lim S, Ismail A I. Sealants and dental caries. J Am Dent Assoc 2011; 142: 1033-1040.

12. Massler M. Preventive endodontics: vital pulp therapy. Dent Clin North Am 1967; (Nov): 663-673.

DOI: 10.1038/sj.bdj.2012.1092

\section{GENERAL AND VAGUE}

Sir, we were interested to read the paper by K. Yip and R. Smales (BDJ 2012; 213: 211-220), in particular, the section on prevention of primary caries, and would like to make a comment on its findings.
We acknowledge the British Dental Journal has an international readership, but it is worth pointing out that in the UK, we are more specific about the level of fluoride that should be added to water when fluoridation schemes are being considered. Yip and Smales say domestic water supplies should be fluoridated at $0.5+\mathrm{ppm}$, however, in the UK, the Water Act of 2003 refers to a 'general target concentration of one milligram per litre', ${ }^{1}$ or one part per million of fluoride.

It is disappointing that Yip and Smales have presented very general and rather vague recommendations on caries prevention. In particular, it is surprising they fail to reference any of the Cochrane reviews on the effectiveness of various fluoride measures. ${ }^{2-5}$

There is also no mention of Delivering better oral health - a publication which was commissioned by the Department of Health. This provides dentists and their teams with evidence-based guidance on the prevention of dental caries. ${ }^{6}$

A copy of this document has been given to all English NHS dentists. It clearly sets out the preventive advice that should be given to patients as well as the effective preventive interventions that should be delivered in the surgery.

The guidance has been very well received. A third edition is currently being developed and will be available in the near future. In the meantime, the second edition of this evidence-based toolkit for prevention is providing the UK dental profession with contemporary, scientifically rigorous guidance on caries prevention. This is something the Yip and Smales paper fails to do.

R. G. Watt, N. Carter, S. Gregory,

B. Cockcroft, S. Makhani, T. Dyer, G. Davies,

D. Richards, D. Thomas, K. Milsom

By email

1. HM Government. Water Act 2003. London: HMSO, 2003

2. Marinho V C, Higgins J P, Sheiham A, Logan S. Fluoride toothpastes for preventing dental caries in children and adolescents. Cochrane Database Syst Rev 2003; CD002278.

3. Marinho V C, Higgins J P, Sheiham A, Logan S. Fluoride varnishes for preventing dental caries in children and adolescents. Cochrane Database Syst Rev 2002; CD002279.

4. Marinho V C, Higgins J P, Sheiham A, Logan S. Fluoride mouthrinses for preventing dental caries in children and adolescents. Cochrane Database Syst Rev 2003; CD002284.

5. Marinho V C, Higgins J P, Sheiham A, Logan S. 
Combinations of topical fluoride (toothpastes, mouthrinses, gels, varnishes) versus single topical fluoride for preventing dental caries in children and adolescents. Cochrane Database Syst Rev 2004; CD002781.

6. Department of Health/British Association for the Study of Community Dentistry. Delivering better oral health: an evidence based toolkit for prevention, 2nd ed. London: Department of Health, 2009.

Professor Roger Smales and Dr Kevin Yip respond: We appreciate the interest of readers in our recent article, in particular the measures that could be included to prevent the development of primary caries.

We also acknowledge that the British Dental Journal has an international readership, which is why we stated that domestic water supplies should be fluoridated at 0.5+ ppm. The additional fluorides that are required to reach the equivalent of approximately $1.0 \mathrm{ppm}$ $(1.0 \mathrm{mg} / \mathrm{L})$ depend very much on the amounts contained in the foods and beverages consumed in the particular locality. In some instances, the domestic fluoridated water originally recommended and supplied at $1 \mathrm{ppm}$ has had to be reduced progressively to $0.5 \mathrm{ppm}$ to maintain the optimum overall effective ingestion level at 1 ppm. ${ }^{1}$ And, as was stated previously, the present series of articles is not intended to be a critical review of each and every topic mentioned.

On the effectiveness of various fluoride measures, we would refer $R$. $G$. Watt et al. to our rather lengthy response to the recent letter of $G$. Yesudain and C. Deery (above), relating to the scant evidence available on the long-term cost-effectiveness in general practice of repeated topical fluoride applications to occlusal pits and fissures in adults in particular. Because the cariostatic effect of fluoride varnishes does not necessarily continue after the cessation of biannual topical applications, ${ }^{2}$ then for how long should such preventive treatments continue and at what costs? There appears to be little benefit from the routine use of professionally applied topical fluorides in patients at low risk for active caries. ${ }^{3}$ Obviously, additional research on many topics related to professionally applied topical fluoride is required and has been recommended. ${ }^{3}$ Rather than employing a routine blanket prescription of professionally applied topical fluorides for caries prevention, we recommend that their use be based on the dental practitioner's assessment of the individual patient's risk for caries, which would also include the availability of fluoridated water supplies.

$R$. G. Watt et al. have a particular interest in promoting the current (and future) edition of Delivering better oral health: an evidence-based toolkit for prevention which, as was stated, all English NHS dentists have already received. And, though in this excellent domestic publication there are very few specific criteria stated for different caries risk levels, and methods for the prevention of secondary (recurrent) caries are not mentioned, we would be happy to include the toolkit in any future Reading list as a very detailed addition to the general advice contained in the present Part 5 article.

1. Evans R W, Stamm J W. Dental fluorosis following downward adjustment of fluoride in drinking water. J Public Health Dent 1991; 51: 91-98.

2. Seppä L, Tuutti H, Luoma H. Post-treatment effect of fluoride varnishes in children with a high prevalence of dental caries in a community with fluoridated water. J Dent Res 1984;63: 1221-1222.

3. American Dental Association Council on Scientific Affairs. Professionally applied topical fluoride. Evidence-based clinical recommendations. J Am Dent Assoc 2006; 137: 1151-1159.

DOI: 10.1038/sj.bdj.2012.1093

\section{ATAVISTIC MALFORMATION}

Sir, the cover photo depiction on the 10 November 2012 issue of the $B D J$ (issue 9) of an open-mouthed African penguin not only portrays the toothlike barbs substituting for absent teeth, but clearly shows the cleft palate naturally occurring in birds and reptiles. The mammalian fused palate separating the oral and nasal cavities is an evolutionary advance enabling mastication, in contrast to gulping food in birds and reptiles. A cleft palate in humans represents a genetically atavistic malformation.

G. H. Sperber Canada DOI: 10.1038/sj.bdj.2012.1094

The $B D J$ website now includes a facility enabling readers to immediately comment on letters. All comments must comply with the nature.com Terms and Conditions and Community Guidelines visit the $B D J$ website to find out more and to post your comment now. 